\title{
Pitaya (Hylocereus spp.) çeliklerinin köklenmesi üzerine bakteri konsantrasyonlarının etkileri
}

\section{Effects of bacteria concentrations on the rooting of pitaya (Hylocereus spp.) cuttings}

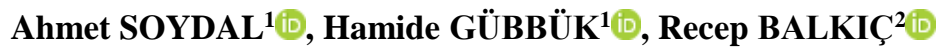 \\ ${ }^{1}$ Akdeniz Üniversitesi, Ziraat Fakültesi, Bahçe Bitkileri Bölümü, 07058, Antalya \\ ${ }^{2}$ Akdeniz Üniversitesi, Elmalı Meslek Yüksekokulu, 07700, Antalya \\ Sorumlu yazar (Corresponding author): H. Gübbük, e-posta (e-mail): gubbuk@akdeniz.edu.tr \\ Yazar(lar)e-posta (Authore-mail): ahmettssoydal@gmail.com, recepbalkic@akdeniz.edu.tr
}

\section{MAKALE BİLGİSİ}

Alınış tarihi 02 Mayıs 2019

Düzeltilme tarihi 17 Ekim 2019

Kabul tarihi 17 Ekim 2019

\section{Anahtar Kelimeler:}

Bloody Mary

Cosmic Charlie

IBA

Kök kalitesi

Köklenme oranı

\begin{abstract}
ÖZ
Pitaya, ülkemiz için yeni bir tropik meyve türdür. Yeni bir türün yaygınlaşması ve bu tür ile ilgili ticari bahçelerin kurulumu, ancak sorunsuz fidan üretimi ile mümkündür. Pitayada, sertifikalı fidan üretimi yapan resmi ya da özel bir kuruluş bulunmamaktadır. Üreticiler, bahçe tesisinde kullanacakları fidanları meyve üretim parsellerinden temin etmektedirler. Bu durum, meyve üretim parsellerinde bitki formunda bozulmalara neden olmaktadır. $\mathrm{Bu}$ nedenle planlanan bu çalışmada, iki pitaya çeşidinde (Bloody Mary ve Cosmic Charlie), çeliklerin köklenmesi üzerine BM-Megaflu'nun etkisi araştırılmıştır. Çelikler $20 \mathrm{~cm}$ uzunluğunda ve bir yıllık sürgünlerden temmuz ayında alınmıștır. Bu amaçla, kontrol ve yaygın olarak kullanılan IBA (3000 ppm) dışında, BM-Megaflu'nun 5000, 10000 ve 15000 ppm'lik konsantrasyonları denenmiştir. Köklendirme sonunda, uygulamaların çeliklerin yaşama oranı, köklenme oranı, primer kök sayısı, kök uzunluğu, en uzun kök uzunluğu ve kök çapı üzerine etkileri incelenmiştir. Yaşama ve köklenme oranı üzerine 3000 ppm IBA uygulamasının, buna karşın kök parametreleri üzerine ise (primer kök sayısı, kök uzunluğu, en uzun kök uzunluğu ve kök çapı) BM-Megaflu uygulamalarının daha iyi sonuç verdiği belirlenmiştir. Çeşitler arasında ise Bloody Mary çeșidinin, Cosmic Charlie'ye göre köklenme oranı ve kök kalitesi açısından daha iyi sonuç verdiği kaydedilmiştir. Araştırma sonucunda, köklenme oranı açısından 3000 ppm IBA ve kök kalitesi açısından ise 15000 ppm BM-Megaflu kullanılması önerilmiştir.
\end{abstract}

\section{ARTICLE INFO}

Received 02 May 2019

Received in revised form 17 October 2019

Accepted 17 October 2019

\section{Keywords:}

Bloody Mary

Cosmic Charlie

IBA

Root quality

Rooting rate

\begin{abstract}
Pitaya is one of the new tropical fruit grown in Turkey. The commercialization of a new species and establishment of plantations can only be possible with the production of seedlings. There are no private or governmental organizations producing pitaya seedlings. Farmers produce seedlings from their fruit production. This situation causes a deterioration of plant forms in the fruit production parcels. The objective of the study is to evaluate the effect of BM-Megaflu on the rooting of the two pitaya cultivars (Bloody Mary and Cosmic Charlie). Cuttings were taken from one year old shoots in July. Except for control and common treatment of IBA (3000 ppm), three different concentrations $(5000,10000$ and $15000 \mathrm{ppm})$ of BM-Megaflu were tested. After rooting, the effects of the treatments on survival rate, rooting rate, number of primary roots, root length and root thickness were examined. Treatment with $3000 \mathrm{ppm}$ IBA gave the best result in terms of survival and rooting rate, however, treatment with BM-Megaflu gave the best results in root quality (the number of primary roots, root length, the longest root length and root thickness). The cultivar Bloody Marry gave better results than Cosmic Charlie in rooting rate and rooting quality. As a result of the study, 3000 ppm IBA was recommended for rooting and 15000 ppm BM-Megaflu for rooting quality.
\end{abstract}

\section{Giriş}

Pitaya (Hylocereus spp.) kaktüsgiller (Cactaceae) familyas1 içerisinde yer almaktadır. Anavatanı, Amerika ve Meksika'nın güneyi ile Kosta Rika, El Salvador, Venezuela, Kolombiya, Ekvador, Panama, Brezilya ve Uruguay olarak bildirmiştir
(Jiang ve Young 2015). Dünyada çilek armudu, pitahaya, tuna, nopal, pitajaya gibi isimlerle anılmaktadır. Ülkemizde ise pitaya ya da ejder meyvesi olarak adlandırılmaktadır. Pitaya yetiştiriciliği dünyada yaygın olarak, Amerika (Florida'nın 
güneyi ve Hawaii), Karayipler, Avustralya, Tayvan, Vietnam, Malezya ve İsrail'de yapılmaktadır. Dünya üretiminde, 30000 ha üretim alanı ve 640000 ton üretim ile Vietnam en yüksek üretim payına sahip ülke konumundadır (Jiang ve Young 2015). Pitaya, dünya için henüz yeni bir meyve türüdür. Zira pitaya, 1990'l yıllara kadar sadece Asya ülkelerinin tükettiği bir meyve türü olarak bilinmekteydi. Avrupa ülkelerinde tüketimi ise ülkemizde olduğu gibi hala sinırlıdır. Bununla birlikte, son y1llarda meyvenin öneminin ortaya çıkması nedeniyle, Avrupa ülkeleri tarafından ithalatı artmaya başlamıştır.

Dünyada pitaya konusunda yapılan çalışmalar, son 20 yıla dayanmaktadır. Nitekim Mizrahi (2015), pitaya ile ilgili 1994 yılına kadar çok sınırlı çalışmaların yapıldığını ve 2015 yılında ise bu tür ile ilgili kayıtlı toplam 284 literatürün bulunduğunu bildirmiştir. Pitayanın, dünyada olduğu gibi ülkemizde de yetiştiriciliği henüz yeni olup, Akdeniz Bölgesi'nin kıyı kesiminde son yıllarda örtüaltında plantasyonlar kurulmaya başlamıştır. Akdeniz Bölgesi'nde en yaygın yetiştirilen iller arasında Mersin, Antalya gösterilebilir. Bununla birlikte, Adana ve Muğla'nın Fethiye ilçesinde de örtüaltında pitaya yetiştiriciliği ile ilgili adaptasyon çalışmaları başlamıştır. Yeni bir türü piyasaya kazandırmak, ancak ismine doğru fidanlar ile bahçe tesis etmekle mümkündür. Son yıllarda ülkemizde, bazı tropik meyve türlerinde tohumdan yetiştirilmiş fidanların satışlarının yapıldığı ve bunların ismine doğru olmaması nedeniyle başarısız sonuçların alındığı (standart meyve elde edilememesi, verim düşüklüğü, kalitenin istenen düzeyde olmamas1) gözlenmiştir. Bu durum, hiç şüphesiz yeni türlerin ticari anlamda yaygınlaşmasını engellemektedir. Diğer meyve türlerinde olduğu gibi tropik meyvelerde de yeni türlerin yaygınlaşması, ancak ismine doğru fidanlarla bahçe tesisi ile mümkündür. $\mathrm{Bu}$ nedenle, ticari anlamda yetiştiricilikte fidan üretimi en önemli hususlardan birisidir.

Pitaya tohumla çoğaltılmakla birlikte, yabancı tozlanmadan dolayı genetik açılma göstermekte ve ayrıca tohumdan çoğaltılan üretim materyalleri ile kurulan bahçelerde gençlik kısırlığından dolayı meyveye yatması uzun süre almaktadır. Bu nedenle, diğer meyve türlerinde olduğu gibi pitayada ticari bahçe kurulumunda vejetatif çoğaltılan üretim materyalleri tercih edilmektedir. Vejetatif çoğaltma metotları içerisinde en yaygın olanı ise çelikle çoğaltmadır. $\mathrm{Bu}$ amaçla çelikler bir y1llık olgunlaşmış sürgünlerden $15-20 \mathrm{~cm}$ uzunluğunda alınmaktadır. Çelikler ya direkt olarak dikilmekte ya da köklendirildikten sonra esas yerlerine aktarılmaktadır. Köklendirmede drenajı iyi olan yetiştirme ortamı (kum, perlit, vermikulit vb.) tercih edilmektedir (Zee ve ark. 2004). Pitayanın vejetatif olarak çoğaltılmasında, çelikle çoğaltmaya ilişkin bazı çalışmalara rastlanmıştır. Çelikle çoğaltmaya ilişkin çalışmalarda, çelik alım bölgeleri, çelik boyu ve çeliklerin dikim derinliği ve hormon kullanımına yönelik çalışmaların yapıldığı dikkati çekmiştir. Çeliklerin köklendirilmesine ilişkin olarak yürütülen çalışmalarda, genellikle indol bütürik asit (IBA) kullanılmış, fakat bakteri kullanımına yönelik herhangi bir çalışma yapılmamıştır.

Çelik alım bölgelerine ilişkin olarak, Cavalcante ve Martins (2008) tarafından yürütülen çalıșmada, bitkilerin üst, orta, alt ve yeni sürgünlerinden alınan çeliklerde, çelik alınan bölgenin köklenme üzerinde etkisi araştırılmıştır. Araştırma sonucunda, çelik alınan bölgenin köklenme üzerine etkili olduğu ve yeni sürgünlerden alınan çeliklerin, diğer bölgelerden alınan çeliklere oranla köklenme oranı açısından daha başarılı olduğu bildirilmiştir.
Çelik boyuna ilişkin olarak yürütülen çalışmada, Marques ve ark. (2011), beş farklı $(5,10,15,20$ ve $25 \mathrm{~cm})$ çelik boyunun köklenme üzerine etkisini araştırmışlardır. Araştırma sonucunda, en uygun çelik boyu 15 ve $25 \mathrm{~cm}$ olarak saptanmıştır. Dikim derinliği üzerinde Marques ve ark. (2012) tarafından yürütülen çalışmada, $20 \mathrm{~cm}$ boyundaki çelikler üç farklı derinlikte $(1,5$ ve $10 \mathrm{~cm})$ dikilmişlerdir. Araştırma sonucunda, dikim derinliği arttıkça kök kuru ağırlığında düşüşler olduğu saptanmıştır. Dikimden 90 gün sonra yapılan gözlemlerde, fidan üretimi için en uygun dikim derinliğinin 1 $\mathrm{cm}$ olduğu bildirilmiştir.

Hormon kullanımında yönelik olarak, Bastos ve ark. (2006) tarafından yürütülen çalışmada, $15-25 \mathrm{~cm}$ boyundaki çeliklerin 3000 ppm IBA konsantrasyonunda 20 saniye süre ile muamelesinin, köklenme oranını arttırdığı kaydedilmiştir. Pontes ve ark. (2014), Brezilya'da pitayada köklenme üzerine IBA ve çelik boyunun etkisini araştırmışlardır. $\mathrm{Bu}$ amaçla yürütülen çalışmada, IBA'nın 4 dozu $(0,1500,3000$ ve 4500 ppm) ve iki farklı çelik boyunun (5-14 cm / 17-26 cm) köklenme üzerine etkisi araştırılmışıtır. Yapılan gözlemler sonucunda, IBA uygulamaları ve çelik boyunun köklenme üzerine etkili olduğu bildirilmiştir. Araştırma bulguları sonucunda, en uygun çelik boyunun $17-26 \mathrm{~cm}$ ve IBA konsantrasyonu ise $3000 \mathrm{ppm}$ olarak saptanmıştır. Seran ve Thiresh (2015), farklı IBA konsantrasyonlarının $10 \mathrm{~cm}$ boyundaki pitaya çeliklerinin köklenmesi üzerine etkilerini araştırmışlardır. Çalışmada kontrol dışında IBA'nın 2000, 4000, 6000 ve 8000 ppm'lik konsantrasyonları denenmiştir. Dikimden 60 gün sonra sökülen çeliklerde yapılan ölçümlerde, 8000 ppm'lik IBA konsantrasyonunun kök uzunluğunu, 6000 ppm IBA'nın ise sürgün uzunluğu ile yaş ve kuru ağırlık bakımından en iyi sonucu verdiği saptanmıştır. Araştırma sonucunda, çeliklerinin köklenmesi üzerine en uygun IBA dozunun 6000 ppm olduğu bildirilmiştir. Pitaya çeliklerinin köklenmesi üzerine Ahmad ve ark. (2016), farklı IBA (kontrol, 50, 75 ve 100 ppm IBA) konsantrasyonlarının etkisini araştırmışlardır Çelikler IBA konsantrasyonunda 10 dakika tutulmuşlardır. IBA konsantrasyonunun artış1 incelenen tüm parametreler üzerinde daha iyi sonuç vermiştir. En yüksek kök sayısı (13.2 adet), en uzun kök uzunluğu $(12.7 \mathrm{~cm})$, kök çapı $(1.5 \mathrm{~mm})$, yaş ağırlık (2.7 g) ve kuru ağırlık (0.8 g)100 ppm IBA uygulamasında ve incelenen tüm kalite kriterleri (sirasiyla 6.3 adet, $5.7 \mathrm{~cm}, 0.9$ $\mathrm{mm}, \quad 0.3 \mathrm{~g}, \quad 0.2 \mathrm{~g}$ ) en düşük kontrol uygulamasında kaydedilmiştir. Araştırma sonucunda, pitaya çeliklerinin köklendirilmesinde 100 ppm IBA uygulaması tavsiye edilmiştir. Pitaya çeliklerinin köklendirilmesinde bakteri kullanımına ilişkin bir literatüre rastlanmamıştır. Bununla birlikte, Gübbük ve ark. (2016) tarafindan yarı odunsu passiflora çeliklerinin köklenmesi üzerine farklı IBA dozları ve bakteri uygulamalarının etkisi araştırılmıştır. Araştırıcılar, farklı dozlarda IBA uygulamalarında köklenme oranını kontrolün bile altında belirlemişlerdir. Buna karşın, bakteri uygulamalarının passiflora çeliklerinde köklenme oranı ve kök kalite parametrelerini olumlu yönde etkilediğini kaydetmişlerdir.

$\mathrm{Bu}$ nedenlerle planlanan araştırmada, kontrol ve 3000 ppm IBA konsantrasyonu ile BM-Megaflu'nun 5000, 10000 ve 15000 ppm'lik konsantrasyonlarının Bloody Mary ve Cosmic Charlie pitaya çeşitlerinde köklenme ve kök kalitesi üzerine etkilerinin incelenmesi amaçlanmıştır. 


\section{Materyal ve Yöntem}

$\mathrm{Bu}$ araştırma, 2017-2018 yılları arasında Akdeniz Üniversitesi, Ziraat Fakültesi, Bahçe Bitkileri Bölümüne ait 1sıtmasız cam serada yürütülmüştür. Araştırmada çeşit olarak, 'Bloody Mary' ve 'Cosmic Charlie' pitaya çeşitleri kullanılmıştır. Bu çeşitlere ait özellikler aşağıda bildirilmiştir.

Bloody Mary: Meyve kabuk rengi kırmızı olup, dış kısmı kırmızı yeşil pullarla kaplıdır. Meyve eti koyu kırmızıdır. Kendine uyuşmaz bir çeşittir. Yabancı tozlanmaya ihtiyaç duymaktadır. Meyve ağırlığı, 230-340 g arasında değişim göstermektedir.

Cosmic Charlie: Meyve kabuğu rengi pembe, dış kısmı kırmızı yeşil pullarla kaplıdır. Kendine verimli bir çeşit olup, meyve ağırlığı ortalama $340-560$ g arasında değişim göstermektedir.

Köklendirmede kontrol, IBA'nın 3000 ppm'lik konsantrasyonu ile BM-Megaflu ticari isimli bakteriyel gübrenin 5000, 10000 ve 15000 ppm'lik konsantrasyonları denenmiştir.

BM-Megaflu'nun kimyasal içeriği ve hazırlama şekli aşağıda bildirilmiştir.

BM-Megaflu: Bacillus megaterium, Pantoea agglomerans ve Pseudomonas fluorescens canlı mikroorganizmalarını içeren mikrobiyal bir gübredir.

BM-Megaflu'nun hazırlanış1: 100 litre suya 1 litre ticari gübre ilave edilmiştir. Bakteri kolonisini arttırmak amacıyla da bu karışıma $500 \mathrm{~g}$ toz şeker ilave edilmiştir.

Köklendirmede kullanılan pitaya çelikleri, Akdeniz Üniversitesi Ziraat Fakültesi Uygulama Arazisindeki donör bitkilerin bir yıllık sürgünlerinden ortalama $20 \mathrm{~cm}$ boyunda ve temmuz ayında alınmıștır. Çelikler IBA'da 20 saniye (Bastos ve ark. 2006) ve BM-Megaflu da ise 60 saniye tutulmuşlardır. Uygulamalardan sonra çelikler perlit içeren sisleme ortamına dikilmişlerdir. Sisleme serasında, sisleme aralığı 10 dakikada 10 saniye olacak şekilde ayarlanmıştır. Çelikler, dikimden 90 gün sonra köklenme ortamında sökülmüş ve aşağıda bildirilen ölçümler yapılmıştır.

1. Canlılık Oranı (\%): Yaşayan çelik sayısı x 100 / toplam çelik sayısı göz önüne alınarak belirlenmiştir.

2. Köklenme Oranı (\%): Köklenen çelik sayısı x $100 /$ toplam çelik sayısı dikkate alınarak hesaplanmıştır

3. Primer Kök Sayısı (adet): Köklenen çeliklerde primer kök sayısı sayılarak belirlenmiştir.

4. Ortalama Kök Uzunluğu (cm): Köklenen çeliklerden tesadüfi olarak seçilen köklerin uzunluğu bir cetvel yardımı ile ölçülerek ortalama olarak belirlenmiştir.

5. En Uzun Kök Uzunluğu (cm): Köklenen çeliklerde, en uzun kökün uzunluğu cetvel yardımı ile ölçülerek kaydedilmiştir.

6. Ortalama Kök Çapı (mm): Köklenen çeliklerden tesadüfi seçilen köklerin çapı dijital kumpas yardımı ile ölçülerek ortalama üzerinden verilmiştir.

7. İstatistiksel Analizler: Araştırma, 3 tekerrürlü ve her tekerrürde 10 çelik olacak şekilde "Tesadüf Parsellerinde
Faktöriyel Düzen” adlı deneme desenine göre planlanmıştır. Uygulamaların karşılaştırılmasında ise LSD testi kullanılmıştır.

\section{Bulgular ve Tartışma}

'Bloody Mary' ve 'Cosmic Charlie' çeşitlerinde, uygulamaların yaşama oranı üzerine etkileri Çizelge 1'de verilmiştir. Bu çizelgeden, çeşit x uygulama interaksiyonu, çeşit ve uygulamaların yaşama oranı üzerine etkileri istatistiksel olarak önemli olduğu görülmektedir. Yaşama oranı üzerine uygulama $\mathrm{x}$ çeşit interaksiyonunun etkisi incelendiğinde, en düşük yaşama oranının \%70 ile Cosmic Charlie çeşidinin kontrol uygulamasında ve en yüksek yaşama oranının ise \%100 ile Bloody Mary çeşidinin 3000 ppm IBA uygulamasında kaydedildiği görülmektedir. Uygulamalar arasında en yüksek yaşama oran $1 \% 95$ ile 3000 ppm IBA uygulamasında saptanmış olup, bu uygulamayı 15000 ppm BM-Megaflu uygulaması takip etmiştir. En düşük yaşama oranı ise \%83.33 ile kontrol uygulamasında kaydedilmiştir. Çeşitler arasında da yaşama oranı bakımından istatistiksel farklılık saptanmış ve en yüksek yaşama oranı \%93.33 ile Bloody Mary çeşidinde belirlenmiştir.

İki farklı pitaya çeşidinde, uygulama x çeşit, uygulama ve çeşitlerin köklenme oranı üzerine etkisi istatistiksel olarak önemli bulunmuştur (Çizelge 2). Köklenme oranı üzerine, uygulama x çeşit interaksiyonunun etkisi incelendiğinde, en düşük köklenme oranının \%70 ile Cosmic Charlie çeşidinin kontrol uygulamasında kaydedildiği ve en yüksek köklenme oranının ise yaşama oranında olduğu gibi \%100 ile Bloody Mary çeşidinin 3000 ppm IBA uygulamasında kaydedildiği Çizelge 2'de görülmektedir. Uygulamalar arasında köklenme oranı bakımından en yüksek değer \%95 köklenme oranı ile 3000 ppm IBA uygulamasında kaydedilmiştir. Çeşitler arasında en yüksek köklenme oranı \%93.33 ile Bloody Mary çeşidinde kaydedilmiştir (Çizelge 2).

Uygulamaların iki pitaya çeşidinde primer kök sayısı üzerine etkileri Çizelge 3 'te verilmiştir. Uygulama $\mathrm{x}$ çeşit interaksiyonunun primer kök sayısı üzerine etkisi incelendiği, en düşük primer kök sayısının 2 adet ile Cosmic Charlie çeşidinin 15000 ppm BM-Megaflu uygulamasında ve en yüksek ise 3.27 adet ile aynı BM-Megaflu konsantrasyonunda Bloody Mary çeşidinde kaydedildiği Çizelge 3'te görülmektedir. Uygulamalar arasında ise primer kök sayısı bakımından istatistiksel farklılık saptanmamıştır. Buna karşın, çeşitlerin primer kök sayısı üzerine etkisi istatistiksel olarak önemli bulunmuş ve en yüksek primer kök sayısı 2.87 adet ile Bloody Mary çeşidinde kaydedilmiştir.

İki farklı pitaya çeşidinde, farklı uygulamaların en uzun kök uzunluğuna etkileri Çizelge 4'te verilmiştir. $\mathrm{Bu}$ çizelgeden, uygulama $\mathrm{x}$ çeşit interaksiyonunun en uzun kök uzunluğu üzerine etkisi istatistiksel olarak önemli olduğu görülmektedir. En uzun kök uzunluğu $36.40 \mathrm{~cm}$ ile Bloody Mary çeşidinin 15000 ppm BM-Megaflu uygulamasında kaydedilmişstir. Uygulamalar arasında, 15000 ppm BM-Megaflu uygulamasının en uzun kök uzunluğu bakımından en iyi sonucu verdiği ve bunu 3000 ppm IBA uygulamasının izlediği görülmektedir. En uzun kök uzunluğu açısından çeşitler değerlendirildiğinde, $33.07 \mathrm{~cm}$ ile en yüksek değerin Bloody Mary çeşidinde kaydedildiği Çizelge 4'ten incelenebilir. 
Çizelge 1. Farklı uygulamaların Bloody Mary ve Cosmic Charlie pitaya çeşitlerinde yaşama oranı üzerine etkileri (\%).

Table 1. The effects of different treatments on the survival rate of Bloody Mary and Cosmic Charlie pitaya cultivars (\%).

\begin{tabular}{|c|c|c|c|}
\hline Uygulamalar & Bloody Mary & Cosmic Charlie & Uygulama Ortalamas1 \\
\hline Kontrol & $96.67 \mathrm{ab}^{*}$ & $70.00 \mathrm{f}$ & $83.33 \mathrm{BC}$ \\
\hline 3000 IBA & $100.00 \mathrm{a}$ & $90.00 \mathrm{~cd}$ & $95.00 \mathrm{~A}$ \\
\hline 5000 BM-Megaflu & $90.00 \mathrm{~cd}$ & $80.00 \mathrm{e}$ & $85.00 \mathrm{BC}$ \\
\hline 10000 BM-Megaflu & $86.67 \mathrm{~d}$ & $76.67 \mathrm{e}$ & $81.67 \mathrm{C}$ \\
\hline 15000 BM-Megaflu & $93.33 \mathrm{bc}$ & $80.00 \mathrm{e}$ & $86.67 \mathrm{~B}$ \\
\hline Çeşit Ortalaması & $93.33 \mathrm{~A}$ & $79.33 \mathrm{~B}$ & \\
\hline $\mathrm{LSD}_{\% 5}$ & eşit: 2.781; & & \\
\hline
\end{tabular}

*LSD testine göre farklı harflerle gösterilen ortalamalar istatistiksel olarak birbirinden farklıdır ( $\mathrm{P} \leq 0.05)$.

Çizelge 2. Farklı uygulamaların Bloody Mary ve Cosmic Charlie pitaya çeşitlerinde köklenme oranı üzerine etkileri (\%).

Table 2. The effects of different treatments on the rooting rate of Bloody Mary and Cosmic Charlie pitaya cultivars (\%).

\begin{tabular}{|c|c|c|c|}
\hline Uygulamalar & Bloody Mary & Cosmic Charlie & Uygulama Ortalamas \\
\hline Kontrol & $96.67 \mathrm{ab}^{*}$ & $70.00 \mathrm{f}$ & $83.33 \mathrm{BC}$ \\
\hline $3000 \mathrm{IBA}$ & $100.00 \mathrm{a}$ & $90.00 \mathrm{~cd}$ & $95.00 \mathrm{~A}$ \\
\hline 5000 BM-Megaflu & $90.00 \mathrm{~cd}$ & $80.00 \mathrm{e}$ & $85.00 \mathrm{BC}$ \\
\hline 10000 BM-Megaflu & $86.67 \mathrm{~d}$ & $76.67 \mathrm{e}$ & $81.67 \mathrm{C}$ \\
\hline 15000 BM-Megaflu & $93.33 \mathrm{bc}$ & $80.00 \mathrm{e}$ & $86.67 \mathrm{~B}$ \\
\hline Çeşit Ortalaması & $93.33 \mathrm{~A}$ & $79.33 \mathrm{~B}$ & \\
\hline$D_{\% 5}$ & Çeşit: 2.78 & & \\
\hline
\end{tabular}

Çizelge 3. Farklı uygulamaların Bloody Mary ve Cosmic Charlie pitaya çeşitlerinde primer kök sayısı üzerine etkisi (adet).

Table 3. The effects of different treatments on the primary root number of Bloody Mary and Cosmic Charlie pitaya cultivars.

\begin{tabular}{cccc}
\hline Uygulamalar & Bloody Mary & Cosmic Charlie & Uygulama Ortalaması \\
\hline Kontrol & $3.07 \mathrm{a}^{*}$ & $2.23 \mathrm{ab}$ & 2.65 \\
3000 IBA & $2.77 \mathrm{ab}$ & $2.83 \mathrm{ab}$ & 2.80 \\
5000 BM-Megaflu & $2.90 \mathrm{ab}$ & $2.63 \mathrm{ab}$ & 2.76 \\
10000 BM-Megaflu & $2.37 \mathrm{ab}$ & $2.23 \mathrm{ab}$ & 2.30 \\
15000 BM-Megaflu & $3.27 \mathrm{a}$ & $2.00 \mathrm{~b}$ & 2.63 \\
\hline Çeşit Ortalaması & $2.87 \mathrm{~A}$ & $2.39 \mathrm{~B}$ & \\
\hline
\end{tabular}

LSD $\% 5$ Uygulama x Çeşit: 1.056; Çeşit: 0.472; Uygulama: Ö.D.**

*LSD testine göre farklı harflerle gösterilen ortalamalar istatistiksel olarak birbirinden farklıdır $(\mathrm{P} \leq 0.05)$. **ö.D. istatistiksel olarak önemli değil.

Çizelge 4. Farklı uygulamaların Bloody Mary ve Cosmic Charlie pitaya çeşitlerinde en uzun kök uzunluğu üzerine etkileri (cm).

Table 4. The effects of different treatments on the longest root length of Bloody Mary and Cosmic Charlie pitaya cultivars (cm).

\begin{tabular}{|c|c|c|c|}
\hline Uygulamalar & Bloody Mary & Cosmic Charlie & Uygulama Ortalaması \\
\hline Kontrol & $35.95 \mathrm{a}^{*}$ & $21.47 \mathrm{f}$ & $28.71 \mathrm{AB}$ \\
\hline 3000 IBA & $30.26 \mathrm{c}$ & $27.35 \mathrm{~d}$ & $28.81 \mathrm{AB}$ \\
\hline 5000 BM-Megaflu & $30.31 \mathrm{c}$ & $21.20 \mathrm{f}$ & $25.76 \mathrm{C}$ \\
\hline 10000 BM-Megaflu & $32.46 \mathrm{~b}$ & $23.52 \mathrm{e}$ & $27.98 \mathrm{~B}$ \\
\hline 15000 BM-Megaflu & $36.40 \mathrm{a}$ & $22.25 \mathrm{ef}$ & $29.33 \mathrm{~A}$ \\
\hline Çeşit Ortalaması & $33.07 \mathrm{~A}$ & $23.16 \mathrm{~B}$ & \\
\hline $\mathrm{LSD}_{\% 5}$ & Çeşit: 0.678 & & \\
\hline
\end{tabular}

* LSD testine göre farklı harflerle gösterilen ortalamalar istatistiksel olarak birbirinden farklıdır $(\mathrm{P} \leq 0.05)$.

Uygulamaların, çeşitlerin ortalama kök uzunluğu üzerine etkileri istatistiksel olarak önemli bulunmuştur (Çizelge 5). Ortalama kök uzunluklarının 16.61 ile $25.41 \mathrm{~cm}$ arasında değiştiği gözlenmiştir. Uygulama $\mathrm{x}$ çeşit interaksiyonunun ortalama kök uzunluğu üzerine etkisi incelendiğinde, en düşük ortalama kök uzunluğunun $16.61 \mathrm{~cm}$ ile Cosmic Charlie çeşidinin kontrol uygulamasında ve en yüksek ortalama kök uzunluğunun ise $25.41 \mathrm{~cm}$ ile Bloody Mary çeşidinin 15000 ppm BM-Megaflu uygulamasında kaydedildiği Çizelge 5'de görülmektedir. Çeşitlerin etkisi incelendiğinde, Bloody Mary çeşidinin Cosmic Charlie çeşidine göre daha uzun kökler oluşturduğu belirlenmiştir (Çizelge 5).
Uygulama $\mathrm{x}$ çeşit interaksiyonunun kök çapı üzerine etkisi incelendiğinde, Bloody Mary çeşidinde 3000 ppm IBA uygulaması $(1.88 \mathrm{~mm})$ ile yine aynı çeşitte $15000 \mathrm{ppm}$ BMMegaflu uygulamasının $(1.86 \mathrm{~mm})$ aynı istatistiksel grup içerisinde yer aldığı Çizelge 6'da görülmektedir. Kök çapı bakımından en düşük değer ise $1.40 \mathrm{~mm}$ ile Cosmic Charlie çeşidinin kontrol uygulamasında saptanmıştır. Uygulamalar arasında, IBA'nın kontrol ve BM-Megaflu uygulamalarına göre kök çapı bakımından daha iyi sonuç verdiği görülmektedir. Kök çapları açısından çeşitler incelendiğinde, incelenen tüm kriterlerde olduğu gibi Blood Mary çeşidi $1.78 \mathrm{~mm}$ ile Cosmic Charlie'den daha iyi sonuç vermiştir (Çizelge 6). 
Çizelge 5. Farklı uygulamaların Bloody Mary ve Cosmic Charlie pitaya çeşitlerinin ortalama kök uzunluğu üzerine etkileri (cm). Table 5. The effects of different treatments on average root length of Bloody Mary and Cosmic Charlie pitaya cultivars (cm).

\begin{tabular}{|c|c|c|c|}
\hline Uygulamalar & Bloody Mary & Cosmic Charlie & Uygulama Ortalaması \\
\hline Kontrol & $24.40 \mathrm{ab}^{*}$ & $16.61 \mathrm{c}$ & 20.51 \\
\hline $3000 \mathrm{IBA}$ & $22.37 \mathrm{abc}$ & $20.07 \mathrm{abc}$ & 21.22 \\
\hline 5000 BM-Megaflu & $22.41 \mathrm{abc}$ & $17.51 \mathrm{bc}$ & 19.96 \\
\hline 10000 BM-Megaflu & $22.37 \mathrm{abc}$ & $16.68 \mathrm{bc}$ & 19.53 \\
\hline 15000 BM-Megaflu & $25.41 \mathrm{a}$ & $17.07 \mathrm{bc}$ & 21.24 \\
\hline Çeşit Ortalaması & $23.39 \mathrm{~A}$ & $17.59 \mathrm{~B}$ & \\
\hline $\mathrm{LSD}_{\% 5}$ & Çeşit: 3.478; & Uygulama: Ö.D:** & \\
\hline
\end{tabular}

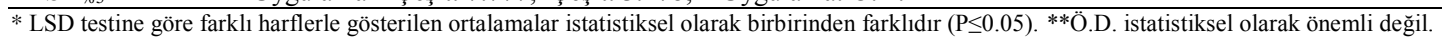

Çizelge 6. Farklı uygulamaların Bloody Mary ve Cosmic Charlie pitaya çeşitlerinde kök çapı üzerine etkileri (mm).

Table 6. The effects of different treatments on root diameter of Bloody Mary and Cosmic Charlie pitaya cultivars (mm).

\begin{tabular}{cccc}
\hline Uygulamalar & Bloody Mary & Cosmic Charlie & Uygulama Ortalamas1 \\
\hline Kontrol & $1.67 \mathrm{~b}^{*}$ & $1.40 \mathrm{~d}$ & $1.53 \mathrm{C}$ \\
3000 IBA & $1.88 \mathrm{a}$ & $1.73 \mathrm{~b}$ & $1.80 \mathrm{~A}$ \\
5000 BM-Megaflu & $1.73 \mathrm{~b}$ & $1.47 \mathrm{~cd}$ & $1.60 \mathrm{C}$ \\
10000 BM-Megaflu & $1.78 \mathrm{ab}$ & $1.47 \mathrm{~cd}$ & $1.61 \mathrm{C}$ \\
15000 BM-Megaflu & $1.86 \mathrm{a}$ & $1.54 \mathrm{c}$ & $1.70 \mathrm{~B}$ \\
\hline Çeşit Ortalamas1 & $1.78 \mathrm{~A}$ & $1.52 \mathrm{~B}$ & \\
\hline
\end{tabular}

LSD $_{\% 5} \quad$ Uygulama x Çeşit: 0.122; Çeşit: 0.547 ; Uygulama: 0.087

* LSD testine göre farklı harflerle gösterilen ortalamalar istatistiksel olarak birbirinden farklıdır $(\mathrm{P} \leq 0.05)$.

İki farklı pitaya çeşidinde, kontrol uygulaması dışında IBA’nın 3000 ppm dozu ve BM-Megaflu ticari isimli bakterinin 3 faklı dozunun $(5000,10000$ ve 15000 ppm) köklenme ve kök kalitesi üzerine etkilerinin denendiği bu çalışmadan, çeşit ve uygulamalara göre farklı sonuçlar alınmıştır. Bulgularımız sonucunda, yaşama ve köklenme oranları benzer sonuçlar göstermiş ve en yüksek yaşama ve köklenme oranları (\%100) Blody Mary çeşidinde 3000 ppm IBA uygulamasından elde edilmiştir. Farklı uygulamaların, kök kalitesini etkileyen ortalama kök uzunluğu, kök çapı ve primer kök sayısı ile en uzun kök uzunluğu bakımından etkileri incelendiğinde ise bulgularımız sonucunda BM-Megaflu uygulamalarının daha etkin olduğu ve en iyi sonucun Blody Mary çeşidinde 15000 ppm BM-Megaflu uygulamasından elde edildiği saptanmıştır. Pitayanın köklenmesi üzerine yapılan literatür taramalarında, genellikle IBA uygulamalarının ön plana çıktığı ve bakteri uygulamalarına rastlanmadığı gözlenmiştir. IBA uygulaması bakımından elde ettiğimiz sonuçlar, Bastos ve ark. (2006)'nın yaptıkları çalışma ile benzer sonuçlar göstermiştir. Bulgularımız yine Pontes ve ark. (2014)'ün sonuçları ile de benzerlik göstermiştir. Zira bu araştırıcılar da ortalama $20 \mathrm{~cm}$ olan çeliklerin köklendirilmesinde, $3000 \quad$ ppm IBA konsantrasyonunun köklenme açısından daha başarılı olduğunu bildirilmişlerdir. Buna karşın, Seran ve Thiresh (2015), $10 \mathrm{~cm}$ boyundaki pitaya çeliklerinin köklendirilmesinde, 6000 ppm IBA nın köklenme oranını arttırdığını bildirmiştir. Bu farklılığın çelik boyundan veya çeşit farklılığından kaynaklandığ düşünülmektedir. Bulgularımızda, BM-Megaflu uygulamalarının çeliklerde özellikle kök kalite kriterlerini olumlu yönde etkilediği görülmektedir. En uzun kök uzunluğu 15000 ppm BM-Megaflu uygulamasinda $36.40 \mathrm{~cm}$ ile en yüksek kaydedilmiş ve bu uygulamayı $35.95 \mathrm{~cm}$ ile 3000 ppm IBA uygulaması izlemiştir. En uzun kök uzunluğu bakımından elde ettiğimiz sonuçlar, Seran ve Thiresh (2015)'in yaptıkları çalışma ile farklılık göstermektedir. Zira bu araştırıcılar, 8000 ppm IBA uygulamasının kök uzunluğunu arttırdığını $(22.00 \mathrm{~cm})$ bildirmişlerdir. Bulgularımızda ise en uzun kök uzunluğu değeri, kök uzunluğu bakımından en düşük değerin elde edildiği $25.76 \mathrm{~cm}$ 'nin bile gerisinde kalmıştır. Sonuçların farklılık göstermesinin nedenleri arasında çelik boyunun, kullanılan çeşitlerin ve ayrıca iklim koşullarının da farklılığından kaynaklanabileceği düşünülmektedir. Yine Ahmad ve ark (2016) tarafından yapılan çalışmada, en uygun IBA konsantrasyonu 100 ppm olarak bildirilmiştir. Bu çalışmada en uygun IBA'nın 100 ppm olarak saptanmasında çeliklerin çözeltide 10 dakika olarak bekletilmesinin rolü olduğu düşünülmektedir. Bulgularımız sonucu, en uzun kök uzunluğu ve kök çapı Ahmad ve ark (2016)'dan daha yüksek kaydedilmiştir.

\section{Sonuç}

Araştırma bulguları sonucunda, köklenme oranı üzerine 3000 ppm IBA'nın etkili olduğu, buna karşın kök kalitesi üzerine ise 15000 ppm BM-Megaflu konsantrasyonunun daha etkili olduğu kaydedilmiştir. Denenen çeşitlerden, Bloody Mary çeşidinin, Cosmic Charlie'ye göre köklenme oranı ve kök kalitesi bakımından daha iyi sonuç verdiği belirlenmiştir. Araştırma bulguları sonucunda, her iki çeşit için köklenme oranı açısından 3000 ppm IBA ve kök kalitesi açısından ise BMMegaflunun 15000 ppm'lik konsantrasyonu önerilmiştir.

\section{Teşekkür}

$\mathrm{Bu}$ araştırma, Akdeniz Üniversitesi Bilimsel Araştırma Projeleri Koordinasyon Birimi (Proje No: FYL-2017-2509) tarafından desteklenmiştir.

\section{Kaynaklar}

Ahmad H, Mirana AS, Mahbuba S, Tareq SM, Jamal Uddin AFM (2016) Performance of IBA concentrations for rooting of Dragon fruit (Hylocereus undatus) stem cuttings. International Journal of Business, Social and Scientific Research 4: 231-234.

Bastos DC, Pio R, Scarpare JA, Libardi MN, Almeida LFP, Galuchi TPD, Bakker ST (2006) Propagation of red pitaya (Hylocereus undatus) by cuttings. Ciencia e Agrotecnologia 30: 1106-1109.

Cavalcante IHL, Martins ABG (2008) Effect of juvenility on cutting propagation of red pitaya. Fruits 63: 277-283.

Gübbük H, Biner B (2016) Passifloranın (Passiflora edulis Sims.) çoğaltılması ve fidan yetiştiriciliği üzerinde araştırmalar. TÜBİTAK proje sonuç raporu, s. 52. 
Jiang Y, Yang W (2015) The effects of heavy shading and flowering thinning in summer on off-season production in red pitaya (Hylocereus sp.). Journal of The Taiwan Society for Horticultural Science 61: 69-77.

Marques VB, Moreira RA, Ramos JD, Araujo NA, Cruz MDM (2011) Cladode size in the production of red pitaya seedlings. Revista Caatinga 24: 50-54.

Marques VB, Moreira RA, Ramos JD, Araujo NA, Cruz MDM (2012) Depth of planting and apical dominance on cuttings of red pitaya. Semina Ciencias Agrarias 33: 2091-2097.

Mizrahi Y (2015) Thirty-one years of research and development in the vine cacti pitaya cultivation in Israel. In: Jiang YL, Liu PC, and
Huang PH (eds.). Improving Pitaya Production and Marketing. Food and Fertlizer Technology Center, Taipei, Taiwan, pp. 1-18.

Pontes FST, Almeida EIB, Barroso MMA, Cajazeira JP, Correa MCD (2014) Length of cuttings and concentrations of indole butyric acid (IBA) in the vegetative propagation of pitaya. Revista Ciencia Agronomica 45: 788-793.

Seran TM, Thiresh A (2015) Root and shoot growth of dragon fruit (Hylocereus undatus) stem cutting as influenced by indole butyric acid. Agricultural and Biological Sciences Journal 1: 27-30.

Zee F, Yen CR, Nishina M (2004) Pitaya (Dragon fruit, strawberry pear). Fruit and Nuts 9: 1-3. 